the area. However, we stand by our conclusions.

It is preceisely because we wished to understand the heterogeneity of results from good services and good studies that we undertook our work. We examined 20 components of home-based care in experimental and control services of published studies. These included, but were not restricted to, ACT studies. Our results (Burns et al, 2001; Catty et al, 2002) show that the clear distinction between ACT and other forms of intensive home-based care that Professor Stein and colleagues insist on, and which Marshall and colleagues (Marshall et al, 1997; Marshall \& Lockwood, 1998) used, simply will not withstand scrutiny. Many of the $A C T$ teams did not have all the 'ACT' characteristics and many of the 'non-ACT' teams had more of them. In short, the groups overlap. It is for this reason that we conducted our regression analysis to determine which components are associated with outcome. Many of these 'effective ingredients' were present in later study control services. We would argue that this is why big differences are no longer being found in US or European studies.

None of this is to take away from the epoch-making impact of Stein and Test's original study. If we are to progress in our understanding of community care, however, we must be prepared to test more sharply-focused questions with increasingly well-designed studies.

BURNS, T., KNAPP, K., CATTY, J., et al (2001) Home treatment for mental health problems: a systematic review. HealthTechnologyAssessment, 5, 1-139.

CATTY, J., BURNS, T., KNAPP, K., et al (2002) Home treatment for mental health problems: a systematic review. Psychological Medicine, 32, 383-401.

MARSHALL, M. \& LOCKWOOD, A. (1998) Assertive CommunityTreatment for People with Severe Mental Disorders. Oxford: The Cochrane Library.

- GRAY, A., LOCKWOOD, A., et al (1997) Case Management for People with Severe Mental Disorder. Oxford: The Cochrane Library.

Tom Burns Professor of Community Psychiatry, Jocelyn Catty Research Fellow, Social and Community Psychiatry, Department of Genera Psychiatry, St George's Hospital Medical School, Jenner Wing, CranmerTerrace, London, SW17 ORE

\section{Good practice of ECT administration}

The audit cycle described by MacEwan (Psychiatric Bulletin, September 2002, 26 337-339) demonstrates a common error in the practice of electroconvulsive therapy (ECT) administration.

Patients who had brief or absent seizures were re-stimulated with higher charges in the practice described by MacEwan. What has not been taken into account is that duration of convulsions also depends on the individual's response to the muscle relaxant and therefore may not accurately reflect the duration of seizure activity in the brain.

Using motor seizures as a measure of effectiveness of the ECT was an excellent idea in the days of unmodified ECT. It must not be forgotten that muscle relaxants are used precisely to stop the convulsions, and therefore it would be erroneous to use the absence of motor seizures as evidence of inadequate stimulation.

Either electroencephalogram (EEG) monitoring, or if resources do not allow this, use of the simple cuff method would be the best way of monitoring the duration of seizures. The fact the restimulation resulted in induction of adequate seizures in only $25 \%$ of cases demonstrates that it may not always be the best course of action.

Lalla \& Milroy (1996) have published a comprehensive review of the literature about seizure duration in the practice of ECT. Their inference from the review is that there is a lack of good evidence to support the contention that longer ECT seizures are more efficacious.

LALLA, F. R. \& MILROY,T. (1996) The current status of seizure duration in the practice of electroconvulsive therapy. Canadian Journal of Psychiatry, 41, 299-304.

Prabhat Mahapatra Consultant Psychiatrist, Care Principles, Dover Road, Barham, Canterbury, CT4 6PW

Dr Mahapatra is correct in his assertion that the method of ECT administration in the audit described was common practice at that time. Indeed in one survey (Robertson et al, 1997), 58\% of clinics in Scotland did not use the cuff technique.

One of the purposes of audit was to examine the effects of a different ECT machine and further training on rates of missed fits. A significant reduction in missed fits was observed.

As discussed in my paper, stimulus titration and EEG monitoring could be considered in future practice and further audit could be carried out.

ROBERTSON, C., FREEMAN, C. P. L. \& FERGUSON, G (1997) ECT in Scotland. Psychiatric Bulletin, 21, 699-702.

Tom MacEwan Consultant in Old Age Psychiatry, Old Age Psychiatry Directorate, Royal Cornhill Hospital, Clerkseat Building, Aberdeen, AB25 2ZH

\section{Audit of antipsychotic and anticholinergic prescribing: Leeds CMHT 2000-1}

We read with interest the paper by Harrington et al (Psychiatric Bulletin,
November 2002, 26, 414-418). It mirrored the results of a recent audit we did on atypical, high dose and co-prescribing of antipsychotics, as well as concurrent anticholinergic prescribing. Drug card information on all general adult inpatients, aged 18-65, prescribed an antipsychotic on a regular basis was collected during a single visit in April 2000. Re-audit occurred in June 2001, and on this occasion adult day hospital patients were included.

Overall, 231 inpatients received a regular prescription for an antipsychotic drug in 2000 and 321 patients in 2001 (213 in-patients and 99 day hospital patients). There were high levels of atypical antipsychotic prescribing (49\%, $95 \%$ confidence interval $[\mathrm{Cl}] 42-55$ in 2000 and $52 \%, 95 \%$ Cl 46-57 in 2001), co-prescribing $(20 \%, 95 \% \mathrm{Cl} 15-26$ in 2000 and $25,95 \% \mathrm{Cl} 20-30$ in 2001) and above British National Formulary (2002) limits prescribing $(15 \%, 95 \% \mathrm{Cl} 11-20$ in 2000 and $17 \%, 95 \% \mathrm{Cl} 12-21$ in 2001) when compared to total antipsychotic prescribing. Furthermore, there were high levels of anticholinergic prescribing with atypical antipsychotics alone $(21,95 \% \mathrm{Cl}$ $13-31$ in 2000 and $18 \%, 95 \% \mathrm{Cl} 12-26$ in 2001).

These prescribing patterns increase the risk of side-effects and negate the cost benefits of atypical antipsychotics. They also run counter to 1993 Royal College of Psychiatrists guidelines on antipsychotic prescribing and World Health Organization anticholinergic prescribing guidelines (World Health Organization, 1990; Barnes, 1990). This audit appears to indicate problems in dissemination and a lack of widespread knowledge of current guidelines.

BARNES,T. R. (1990) Comment on theWHO consensus statement: prophylactic use of anticholinergics in patients on long-term neuroleptic treatment. British Journal of Psychiatry, 156, 412.

BRITISH NATIONAL FORMULARY (2002) BNF 43, March. London: British Medical Association \& Royal Pharmaceutical Society.

ROYAL COLLEGE OF PSYCHIATRISTS (1993) Consensus Statement on the Use of High DoseAntipsychotic Medication. Council Report CR26. London: Royal College of Psychiatrists.

WORLD HEALTH ORGANIZATION (1990) Prophylactic Use of Anticholinergics in Patients on Long-term Neuroleptic Treatment. A Consensus Statement. Geneva: World Health Organization

Emma Whicher Senior House Officer, Jane Riley Pharmacist, Leeds Community Mental Health Trust, The Andrew Sims Centre, High Royds Hospital, Bradford Road, Menston LS29 6AQ

\section{From couch to coach}

The Football Association (FA) launched its strategy "Psychology for Football" at the Pride Park Stadium, Derby, on 